\title{
CHROMOSOME BALANCE AND ENDOSPERM FAILURE IN HYACINTHS
}

\author{
R. D. BROCK \\ John Innes Horticultural Institution, Hertford, Herts. and \\ Division of Plant Industry, C.S.I.R.O., Canberra, A.C.T. Australia
}

\section{INTRODUCTION}

Received 9.ix.54

FAILURE of endosperm resulting in failure of an otherwise normal embryo is a widespread occurrence following crosses between species, between plants of different chromosome number and on selfing normal outbreeders. Various suggestions have been made as to the cause of the breakdown (see Brink and Cooper, r947 ; Beaudry, 195 I ; Brock, 1954). These suggestions mainly concern chromosomal, genic or cytoplasmic unbalances in the endosperm, or between endosperm, embryo and maternal tissue or between endosperm and antipodals.

The mechanism of endosperm failure in Lilium hybrids has been shown to be the accumulation of mitotic abnormalities, resulting from spontaneous chromosome breakage. These reduce the mitotic activity and culminate in degeneration of the endosperm and failure of the embryo (Brock, 1954).

Hyacinthus orientalis was selected for further work on this problem because of its triploid endosperm, its suitability for cytological examination and the unusual situation of chromosome balance operating in this species (Darlington and Mather, 1944; Darlington et al., 1951).

As a result of an internal chromosome balance, viable gametes with different chromosome numbers are produced by aneuploid and triploid hyacinth varieties. Thus endosperms can be produced which differ in chromosome number. Endosperm failure can thus be studied in relation to both genetic and chromosomal variables.

\section{METHODS}

Hyacinth varieties were selfed and cross pollinated without prior emasculation. No ovules developed after selfing. Ovules from Lady Derby crossed Duke of York and the reciprocal cross were fixed at 5 -day intervals for 30 days. In all other crosses the ovules were fixed between 12 and 16 days after pollination. At each fixation and when harvesting the mature seeds, the total ovules and the numbers of developing and degenerating ovules were recorded.

Fixations 5 days after pollination were made in Navashin's fluid (Darlington and $\mathrm{La}$ Cour, 1947). These were embedded in wax, section cut $16 \mu$ thick and stained in crystal violet. All other fixations were made in Carnoy's fluid $(6: 3: 1)$. After storage in absolute alcohol, I to 14 days, ovules were hydrolysed for 13 minutes in $\mathrm{N} / \mathrm{r} \mathrm{HCl}$ and stained in Feulgen reagent. The embryo and endosperm were dissected and squashed in 45 per cent. acetic acid. Slides were made permanent by mounting in Euparal.

In the X-ray experiments pollen and ovules were irradiated immediately before pollination, developing endosperms 9,12 and 13 days after pollination. All 
fixations were made 14 days after pollination. The irradiation was unfiltered at $70 \mathrm{Kv}$. and $5 \mathrm{~m} . \mathrm{a}$., focal distance $20 \mathrm{~cm}$., dosage rate $5^{\mathrm{I}} \cdot 5$ Röntgen units per minute. Total dose for pollen and unfertilised ovules was $500 \mathrm{r}$ and for endosperms roo r.

\section{CHROMOSOMES OF THE VARIETIES}

One of the reasons for choosing hyacinth for this work was the variation in its chromosome complement. Darlington et al. (1951) have described the chromosomes of 106 varieties. For convenience the chromosome complement of the varieties now used is given in table I.

TABLE I

Somatic chromosome complements of hyacinth varieties

\begin{tabular}{|c|c|c|c|c|c|}
\hline & \multicolumn{5}{|c|}{ Chromosome complement } \\
\hline & L & $L^{n}$ & $\mathbf{M}$ & $\mathrm{S}_{1}$ & $\mathrm{~S}_{2}$ \\
\hline $\begin{array}{l}2 x- \\
\text { Borah . } \\
\text { Cherry Blossom } \\
\text { Early Roman } \\
\text { H. orientalis . }\end{array}$ & 6 & 2 & 4 & 2 & 2 \\
\hline & \multicolumn{5}{|c|}{ Extra chromosomes } \\
\hline $\begin{array}{l}3 x- \\
\text { King of the Blues } \\
\text { Lady Derby }\end{array}$ & 3 & I & 2 & I & 1 \\
\hline $\begin{array}{l}\text { Hypo-3x- } \\
\text { Rosalie }(2 x+1) \\
\text { Duke of York }(2 x+6)\end{array}$ & 3 & $\begin{array}{l}1 \\
1\end{array}$ & $\ldots$ & 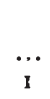 & $\dddot{r}$ \\
\hline
\end{tabular}

Note.--The chromosome complement of Duke of York used here has seven chromosomes less than that given by Darlington et al. (1951). My plants were obtained from a different source and probably represent a misnomer due to the mauve flower colour of the two clones.

The haploid set of eight consists of four long chromosomes, (L), one of which carries the nucleolar organiser $\left(\mathrm{L}^{n}\right)$; two medium chromosomes (M); and two short chromosomes which can be separated on the position of the centromere into $S_{1}$ and $S_{2}$.

Five plants of $H$. orientalis collected in Palestine by Major A. E. Pam were used. Two were normal diploids, the other three each had a deficiency of the whole of the long arm of one of the $\mathrm{S}_{2}$ chromosomes.

Nucleolar constriction. In the rapidly dividing endosperm the chromosomes at metaphase are incompletely spiralised and they are in general 20 to 25 per cent. longer than root tip chromosomes. The nucleolar constriction is much attenuated and two types of $\mathrm{L}^{n}$ chromosomes are recognisable in the endosperm. In one type the nucleolar 
constriction is very long and appears as a weakly staining gap in the chromosome. In the other the nucleolar constriction is shorter and has three deeply staining knobs in it (pl. r, fig. 2). These two types of $\mathrm{L}^{n}$ chromosomes can occasionally be recognised in root tip preparations (Darlington et al., 1951) but here, owing to the greater spiralisation, only slight differences in the length of the constriction are observed. From the crosses that have been examined it appears that Borah, King of the Blues, Lady Derby and Rosalie are heterozygous for this condition; Early Roman and $H$. orientalis had only the type with the shorter constriction with staining areas and Cherry Blossom only long constrictions.

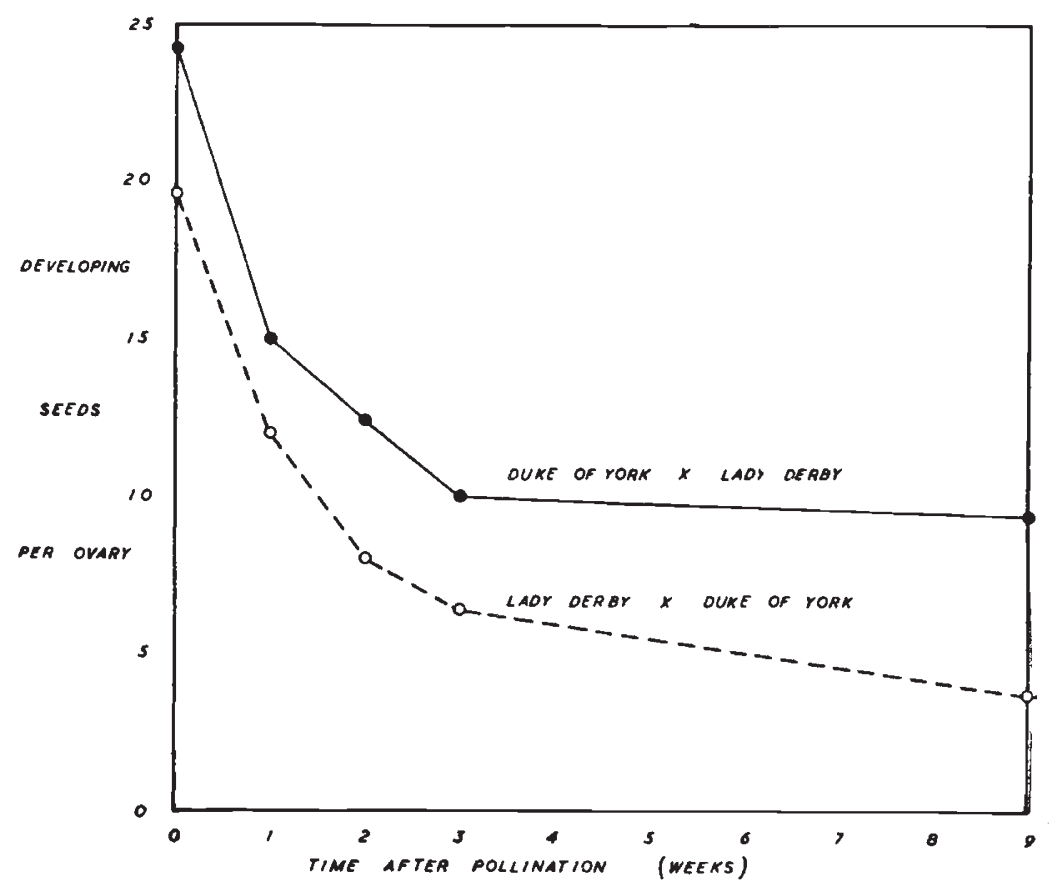

FIG. 1.-Graph showing failure of developing seeds in reciprocal hyacinth crosses at various times after pollination.

The staining areas in the attenuated constriction region probably represent small structural changes in the chromosomes.

\section{CROSSING AND SEED SET}

No ovules developed or seeds set after self pollination but many crosses between the varieties were successful. The seed set per ovary was low in all crosses. Examinations at intervals after pollination showed that the main period of failure of the developing seeds was during the first three weeks after pollination (fig. I). This was due to the failure of the endosperm and subsequent abortion of the embryo and is comparable to the endosperm failure previously reported in Lilium. As in Lilium no mitotic abnormalities occurred in the hyacinth 
embryos. The mitotic abnormalities in the hyacinth endosperms were not, however, so severe as those in Lilium. This may have been due in part to the triploidy of the hyacinth endosperm as opposed

TABLE 2

Hyacinth variety crosses and chromosome complements of resulting endosperms 12 to 16 days after pollination

\begin{tabular}{|c|c|c|c|c|c|c|c|c|}
\hline \multirow{2}{*}{$\begin{array}{l}\text { Cross } \\
q \text { by }{ }^{\prime}\end{array}$} & \multirow{2}{*}{$\begin{array}{c}\text { No. of } \\
\text { endosperms }\end{array}$} & \multicolumn{5}{|c|}{ Chromosome complement } & \multicolumn{2}{|c|}{ Mean chromosome no. } \\
\hline & & $3^{n}$ & $\mathbf{L}$ & $\mathrm{L}^{n}$ & $\mathbf{M}$ & S & Expected & Observed \\
\hline $2 x$ by $2 x$ & 8 & 24 & 9 & 3 & 6 & 6 & $24^{\circ} \mathrm{O}$ & $24 \cdot 0$ \\
\hline $2 x$ by $2 x+1$ & I & 24 & 9 & 3 & 6 & 6 & $24 \cdot 5$ & 24.0 \\
\hline $2 x+1$ by $2 x$ & $\begin{array}{r}16 \\
6\end{array}$ & $\begin{array}{l}24 \\
26\end{array}$ & $\begin{array}{l}9 \\
9\end{array}$ & $\begin{array}{l}3 \\
5\end{array}$ & $\begin{array}{l}6 \\
6\end{array}$ & $\begin{array}{l}6 \\
6\end{array}$ & 25.0 & $24 \cdot 5$ \\
\hline \multirow[t]{7}{*}{$2 x+1$ by $3^{x}$} & I & $3^{I}$ & 12 & 5 & 6 & 8 & & \\
\hline & I & $3^{1}$ & 12 & 3 & 9 & 7 & & \\
\hline & I & 29 & 12 & 3 & 7 & 7 & & \\
\hline & 2 & 29 & II & 4 & 7 & 7 & & \\
\hline & I & 28 & 12 & 4 & $6 ?$ & 6 & & \\
\hline & I & 27 & 12 & 3 & 6 & 6 & & \\
\hline & $\begin{array}{l}1 \\
1\end{array}$ & $\begin{array}{l}27 \\
27\end{array}$ & II & $\begin{array}{l}3 \\
3\end{array}$ & 6 & 7 & $29 \cdot 0$ & $28 \cdot 7$ \\
\hline \multirow[t]{4}{*}{$2 x+6$ by $2 x$} & I & $3^{2}$ & 13 & 5 & 6 & 8 & & \\
\hline & i & 30 & 13 & 5 & 6 & 6 & & \\
\hline & I & 28 & 13 & 3 & 6 & 6 & & \\
\hline & I & 26 & II & 3 & 6 & 6 & $30^{\circ} 0$ & $29 \cdot 0$ \\
\hline \multirow{14}{*}{$3 x$ by $2 x$} & 3 & 38 & 15 & 5 & 8 & 10 & & \\
\hline & I & 36 & 15 & 3 & 8 & 10 & & \\
\hline & I & 34 & 13 & 5 & 8 & 8 & & \\
\hline & I & 34 & 11 & 5 & 10 & $8 ?$ & & \\
\hline & I & $3^{2}$ & 13 & 3 & 8 & 8 & & \\
\hline & I & $3^{2}$ & in & 5 & 10? & 6 & & \\
\hline & I & $3^{2}$ & II & 5 & 8 & 8 & & \\
\hline & I & $3^{2}$ & II & 5 & 6 & Io & & \\
\hline & I & 30 & 13 & 3 & 8 & 6 & & \\
\hline & i & 30 & II & 5 & 8 & 6 & & \\
\hline & I & 30 & II & 5 & $\begin{array}{l}6 \\
8\end{array}$ & 8 & & \\
\hline & I & 28 & 9 & 5 & 8 & 6 & & \\
\hline & 1 & 26 & II & 3 & 6 & 6 & & \\
\hline & I & 26 & 9 & 3 & 6 & 8 & $32 \cdot 0$ & $32 \cdot 2$ \\
\hline \multirow{5}{*}{$3^{x}$ by $2 x+1$} & 1 & 37 & 13 & 6 & 8 & 10 & & \\
\hline & 1 & $3^{2}$ & 15 & 3 & 8 & 6 & & \\
\hline & I & $3^{2}$ & 13 & 3 & 6 & Io & & \\
\hline & I & 32 & 9 & 5 & 10 & 8 & & -8 \\
\hline & I & 26 & II & 3 & 6 & & $32 \cdot 5$ & $3^{1 \cdot 8}$ \\
\hline
\end{tabular}

to its pentaploidy in Lilium. On the other hand the hyacinth's aneuploids are almost as satisfactory as balanced multiples of the chromosome set: the hyacinth can afford these errors because of its unusual chromosome balance. 


\section{CHROMOSOME BALANCE}

The distribution of different types of chromosomes has been studied by Darlington and Mather (1944) in pollen grains of triploid hyacinths and by Darlington et al. (I95I) in aneuploid commercial hyacinth varieties. The pollen grains were virtually unselected and demonstrate the balance between the chromosomes. The horticultural varieties, which have been selected both for vigour and flower characters, indicate not only the breeder's preference but also the chromosome complements which are favoured as a permanent basis of growth.

From studies on pollen grains of triploid hyacinths the total loss of chromosomes at meiosis has been placed at ro per cent. by Belling (1924), Darlington (1926) and Darlington and Mather (1944) and at 5 per cent. by Darlington et al. (195I). These last two papers also establish the principle that there is an increasing frequency of loss at meiosis with decreasing chromosome size.

TABLE 3

Contribution of extra chromosomes in gametes which were successful in crosses (table 2). The complements of the gametes calculated from the endosperm complement (table 2) and the known complement of one gamete $\left(x\right.$ or $\left.x+L^{n}\right)$. Calculation based on monosporic embryo sac development (Anderson, 1936)

\begin{tabular}{|c|c|c|c|c|c|c|}
\hline \multirow{3}{*}{ Parent } & \multicolumn{3}{|c|}{ q } & \multicolumn{3}{|c|}{$\sigma$} \\
\hline & \multirow{2}{*}{$\begin{array}{l}\text { No. of } \\
\text { gametes }\end{array}$} & \multicolumn{2}{|c|}{ Extra chromosomes } & \multirow{2}{*}{$\begin{array}{l}\text { No. of } \\
\text { gametes }\end{array}$} & \multicolumn{2}{|c|}{ Extra chromosomes } \\
\hline & & $\begin{array}{l}\text { Mean per } \\
\text { gamete }\end{array}$ & $\begin{array}{c}\text { Loss or } \\
\text { gain }\end{array}$ & & $\begin{array}{l}\text { Mean per } \\
\text { gamete }\end{array}$ & $\begin{array}{l}\text { Loss or } \\
\text { gain }\end{array}$ \\
\hline $2 x+1$ & $3^{I}$ & 0.23 & -0.27 & 6 & 0.17 & -0.33 \\
\hline $2 x+6$ & 4 & $2 \cdot 5$ & -0.50 & $\ldots$ & $\ldots$ & $\ldots$ \\
\hline $3^{x}$ & 21 & $4 \cdot 0$ & $o$ & 9 & 4.3 & +0.3 \\
\hline
\end{tabular}

Darlington et al. (1951) examined the chromosome balance in somatic cells of commercial hyacinth varieties. They found a correlation between $\mathrm{L}$ and $\mathrm{M}+\mathrm{S}$ chromosomes which depended on the absence of certain unbalanced types $(4: 2$ and $2: 4)$. There were correlations between the numbers of extra $\mathbf{M}$ and $\mathbf{S}$ chromosomes and between the extra $\mathrm{L}$ and $\mathrm{L}^{n}$ chromosomes. There was also a preference for odd numbers of $\mathrm{L}$ and $\mathrm{S}$ chromosomes and even numbers of $\mathbf{M}$ chromosomes.

Developing seeds represent an intermediate step in the selection processes. Chromosome complements have been determined in the endosperm, and in some cases in the embryo also, of hybrids 12 to I 6 days after pollination (table 2). At this time the embryo consisted 
of 16 to 25 cells and the endosperm 250 to 500 free nuclei in a common cytoplasm. Mitoses in the endosperm were synchronous.

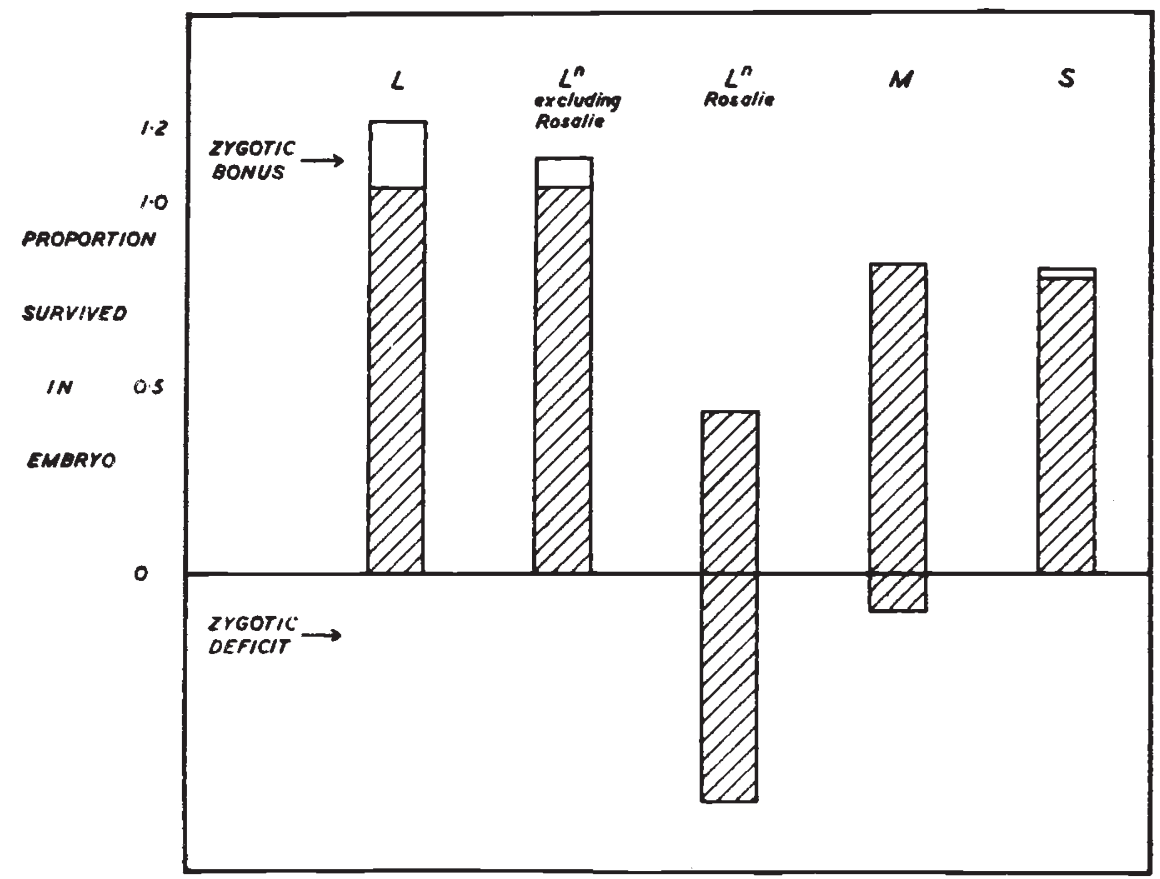

Fig. 2.- Survival of chromosomes of each type in pollen grains (hatched), from Darlington et al. (1951), compared with survival in embryo 12 to 16 days after various crosses (table 2). Survival of $\mathrm{L}$ and $\mathrm{L}^{n}$ not shown separately by Darlington et al. (1951), their combined figure for $\mathrm{L}+\mathrm{L}^{n}$ is compared with both $\mathrm{L}$ and $\mathrm{L}^{n}$ in embryos. Zygotic bonus (clear) represents increased survival and zygotic deficit decreased survival in embryos.

CHROMOSOME BREAKAGE

IN ENOOSPERM

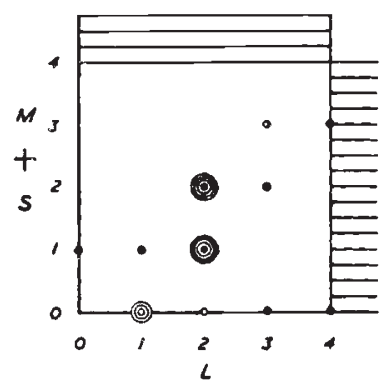

NORMAL ENDOSPERM

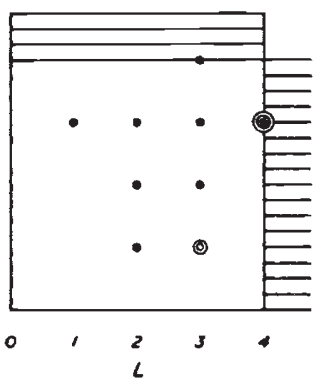

COMMERCIAL VARIETIES

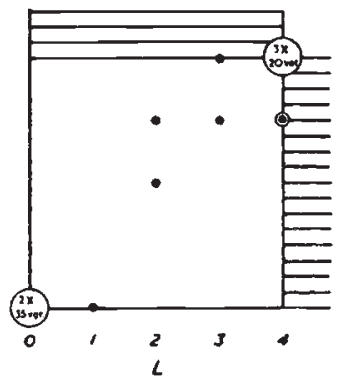

Fig. 3.-Relation of $\mathrm{L}$ to $\mathrm{M}+\mathrm{S}$ in the extra chromosomes of hyacinths. Hybrid embryos, 12 to 16 days after pollination, from the various crosses (table 2) compared with commercial varieties (Darlington et al., 1951). Each circle represents one variety or hybrid. The four crosses involving Duke of York $(2 x+6)$ indicated by open circles. Rosalie by diploid crosses not included (see table 5 ). $\mathrm{L}=\left(\mathrm{L}+\mathrm{L}^{n}\right)$.

Knowing the chromosome complements of the endosperm and one gamete, the complements of the other gamete and the embryo can be calculated. 
TABLE 4

Number of extra chromosomes of each type, derived from $q$ and $\delta$ parents surviving in embryos 12-16 days after various crosses (table 2)

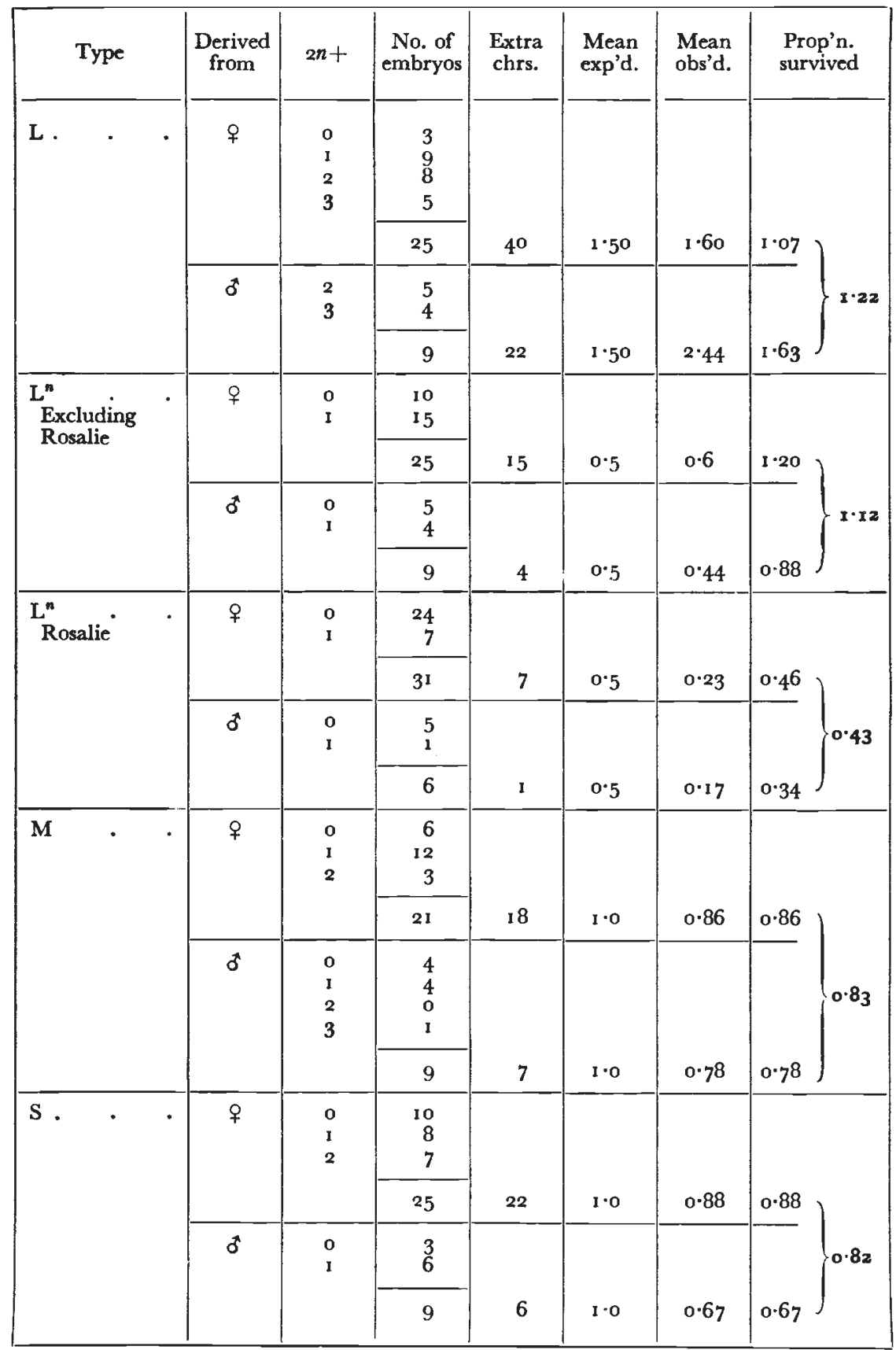

$\mathrm{L}^{n}$ excluding Rosalie : $\mathrm{L}^{n}$ Rosalie. $\chi^{2}=1 \mathrm{I} \cdot 4 ; \mathrm{P}<0 \cdot 01$. 
The successful gametes from the triploid parents had a mean of four extra chromosomes per gamete (table 3 ). This suggests no loss of chromosomes at meiosis and is contrary to the previous accounts (Belling, 1924; Darlington, 1926 ; Darlington and Mather, 1944; and Darlington et al.). Examination of the survival of the individual types of chromosomes in the embryo reveals that there was, in fact,

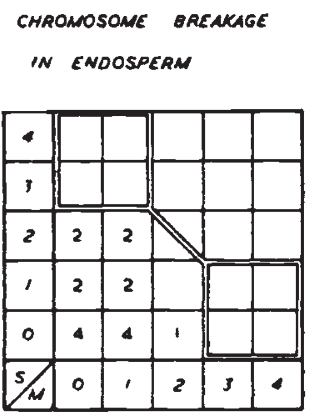

NORMAL ENDOSPERM

CONMERCIAL VARIETIES
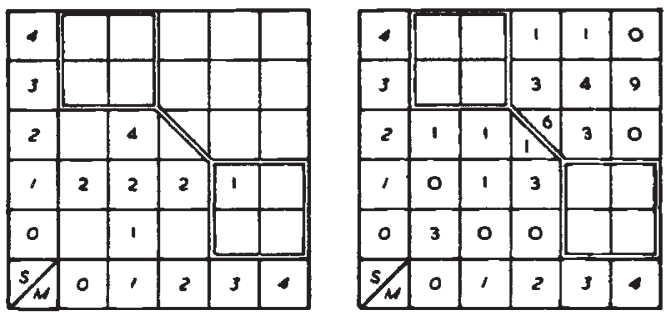

Fig. 4.-Relation of $M$ to $S$ in the extra chromosomes of hyacinths. Comparison of developing seeds and commercial varieties. The same varieties and hybrids as in fig. 3 except that the Duke of York $(2 x+6)$ crosses are excluded.

loss at meiosis. This loss agreeing with the principle that in polysomic plants there is an increasing frequency of loss at meiosis with decreasing chromosome size (table 4, fig. 2). These embryos therefore represent selective fertilisation by the gametes with higher chromosome number or selective survival of embryos resulting from fertilisation with such gametes.

TABLE 5

Relation of odd to even numbers in each type of chromosome in embryo 12-16 days after pollination

\begin{tabular}{|c|c|c|c|c|c|c|c|c|}
\hline & \multicolumn{8}{|c|}{ Chromosomes in embryo } \\
\hline & \multicolumn{2}{|c|}{$\mathbf{L}$} & \multicolumn{2}{|c|}{$\mathbf{M}$} & \multicolumn{2}{|c|}{$\mathbf{S}$} & \multicolumn{2}{|c|}{$\mathbf{M}+\mathbf{S}$} \\
\hline & Odd & Even & Odd & Even & Odd & Even & Odd & Even \\
\hline No breakage in endosperm. & 7 & 7 & 8 & 4 & 8 & 6 & I0 & 4 \\
\hline Breakage in endosperm & 7 & 12 & 8 & 9 & 4 & 15 & 8 & II \\
\hline Total & 14 & 19 & 16 & $\mathbf{2 3}$ & 22 & $2 x$ & 18 & 15 \\
\hline $\begin{array}{l}\text { Commercial varieties prefer- } \\
\text { ence for }\end{array}$ & \multicolumn{2}{|c|}{ Odd } & \multicolumn{2}{|c|}{ Even } & \multicolumn{2}{|c|}{ Odd } & \multicolumn{2}{|c|}{ Odd? } \\
\hline
\end{tabular}

The chromosome complements of the embryos confirm the number relations of $\mathrm{L}$ to $\mathrm{M}+\mathrm{S}$ chromosomes evident in the established varieties (fig. 3). However, the preference for the odd numbers of $\mathrm{L}$ and $\mathrm{S}$ 
chromosomes and even numbers of $\mathbf{M}$ chromosomes observed in the commercial varieties is not confirmed in either the total embryos or those with endosperms which showed no chromosome breakage (table 5 , fig. 4). Also there are exceptions to the selective concentrations of extra $\mathbf{M}$ and $\mathrm{S}$ chromosomes and the number relations of $\mathrm{L}$ to $\mathrm{L}^{n}$ chromosomes outlined by Darlington et al. (I95I). Perhaps these represent chromosome combinations which, although surviving the selective mechanism of endosperm failure, will be eliminated by later selection processes.

One notable exception results from an unusual male gamete from the triploid King of the Blues. This gamete had a complement $6: 1: 5: 3$, and was formed by 5 of the $6 \mathrm{M}$ chromosomes segregating into the one pollen grain. This could only occur by illegitimate

TABLE 6

Number of abnormal endosperms in various hyacinth crosses, 12-16 days after pollination

\begin{tabular}{|c|c|c|c|c|c|c|}
\hline \multirow[b]{2}{*}{$\begin{array}{l}\text { Cross } \\
q \text { by }{ }^{*}\end{array}$} & \multirow{2}{*}{$\begin{array}{l}\text { Mean } \\
\text { extra } \\
\text { chrs. }\end{array}$} & \multicolumn{5}{|c|}{ Number of endosperms } \\
\hline & & Total & $\begin{array}{l}\text { Degener- } \\
\text { ating }\end{array}$ & Dividing & $\begin{array}{l}\text { Sub-chrd. } \\
\text { and chr. } \\
\text { breakage }\end{array}$ & $\begin{array}{l}\text { Spindle } \\
\text { errors }\end{array}$ \\
\hline $2 x$ by $2 x$ & o & 283 & 3 & 17 & 6 & 2 \\
\hline $\begin{array}{l}2 x \text { by } 2 x+1 \\
2 x+1 \text { by } 2 x\end{array}$ & $\left.\begin{array}{l}0 \cdot 5 \\
1 \cdot 0\end{array}\right\}$ & 501 & 6 & 39 & I 4 & 6 \\
\hline $\begin{array}{l}2 x \text { by } 3^{x} \cdot \\
2 x+1 \text { by } 3^{x}\end{array}$ & $\left.\begin{array}{l}4 \cdot 0 \\
5 \cdot 0\end{array}\right\}$ & 436 & 13 & 26 & 11 & 5 \\
\hline $\begin{array}{l}3 x \text { by } 2 x \\
3^{x} \text { by } 2 x+1\end{array}$ & $\left.\begin{array}{c}8 \cdot 0 \\
8 \cdot 5\end{array}\right\}$ & 906 & $4 \mathrm{I}$ & 65 & 40 & 18 \\
\hline \multirow[t]{2}{*}{$\begin{array}{l}2 x+6 \text { by } 3 x \\
3 x \text { by } 2 x+6\end{array}$} & $\left.\begin{array}{l}10 \cdot 0 \\
11 \cdot 0\end{array}\right\}$ & $75^{8}$ & 36 & 59 & $3^{8}$ & I3 \\
\hline & & 2884 & 99 & 206 & 109 & 44 \\
\hline
\end{tabular}

segregation of a univalent or by quadrivalent formation (which has not been reported in triploid hyacinths).

Early degeneration of the developing seeds and chromosome breakage in the endosperm both increase in frequency as the chromosome number of the parent varieties is increased (table 6, fig. 5). Although there is this relationship between chromosome number and failure of the endosperm it is also apparent that abnormalities occur where there are no extra chromosomes (diploid by diploid crosses).

Rosalie. The extra $\mathrm{L}^{n}$ chromosome in Rosalie was less readily transmitted to the embryo and endosperm than the extra chromosomes of other varieties (tables 2, 3, 4). 
At first metaphase of meiosis in Rosalie, chiasma frequency is high, mean chiasma frequency per potential bivalent in ro cells was $2 \cdot 84$, and the $\mathrm{L}^{n}$ chromosomes formed trivalents in 40 of 47 cells. A high frequency of bridges and fragments, resulting from crossing

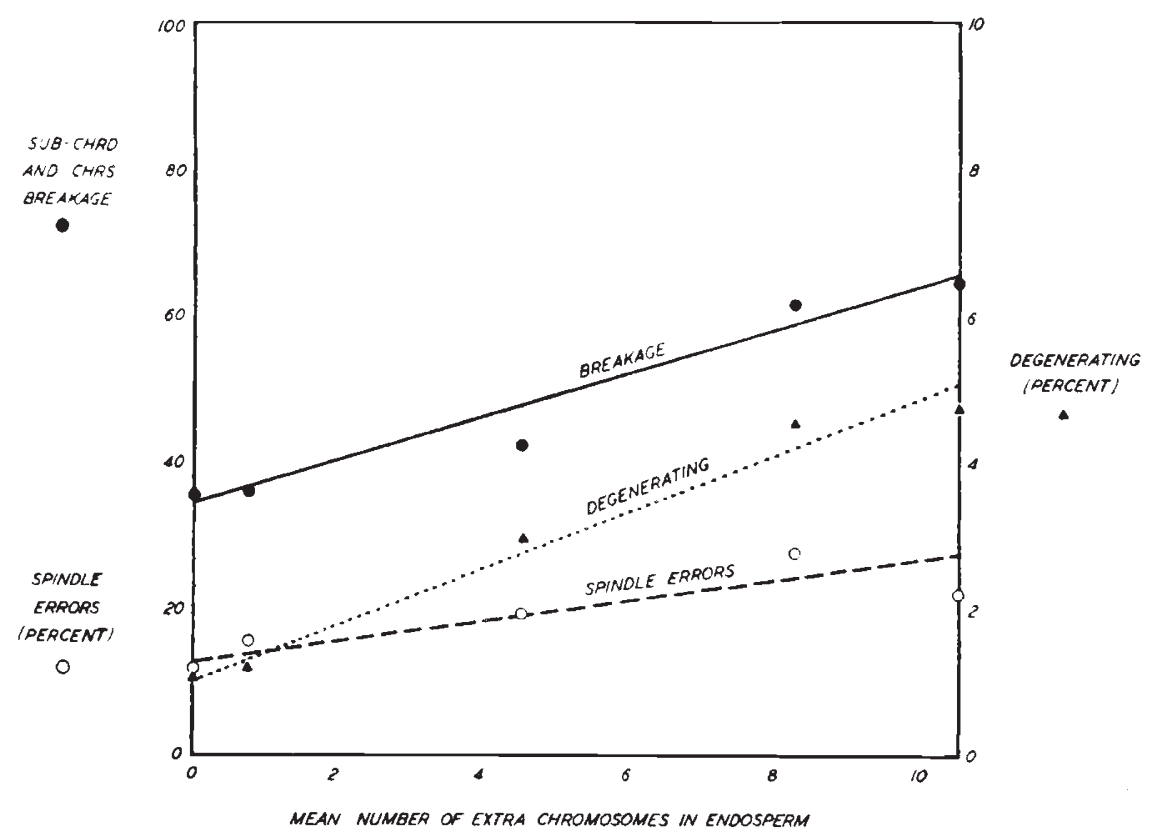

Fig. 5.-Graph showing relation of extra chromosomes in hyacinth endosperms to chromosome breakage, degeneration and spindle abnormalities. Various crosses (table 2), 12 to 16 days after pollination.

over in inverted segments, occurred at A I and A II (table 7). These always involved $\mathrm{L}$ and never $\mathrm{L}^{n}$ chromosomes. Several first anaphases had two separate bridges and fragments and one mother cell at A II had bridges and fragments in each of the two daughter cells. Short

TABLE 7

Inversion crossing over (I.C.O.) frequency at meiosis in the variety Rosalie

\begin{tabular}{|c|c|c|c|c|}
\hline \multicolumn{2}{|c|}{ A I } & \multicolumn{2}{|c|}{ A II } & $\begin{array}{c}\text { I.C.O. } \\
\text { frequency }\end{array}$ \\
\hline Mother cells & $\mathbf{b}+\mathbf{f}$ & Mother cells & $\mathbf{b}+\mathbf{f}$ & \\
\hline 235 & 98 & 155 & $3^{8}$ & $\mathbf{0} 666$ \\
\hline
\end{tabular}

Note.-I.C.O. frequency calculated by adding together the frequencies of bridges at first and second division per mother cell (Darlington, 1937, p. $27 \mathrm{r}$ ).

fragments were most frequent but occasionally a long fragment accompanied by a short bridge occurred. Thus at least two pairs of $\mathrm{L}$ chromosomes had relatively inverted segments. 
At second division of meiosis daughter cells were always synchronised and there was no evidence of any loss of $\mathrm{L}^{n}$ chromosomes.

Counts at pollen grain mitosis showed only 16.5 per cent. of cells with the extra $\mathrm{L}^{n}$ chromosome and less than 3 per cent. of cells with evidence of chromosome breakage (table 8). At this stage approximately 30 per cent. of the pollen grains were degenerating and appeared

TABLE 8

Numbers of pollen grains of Rosalie (trisomic for $L^{n}$ ) with $I$ or $2 L^{n}$ chromosomes

\begin{tabular}{|c|c|c|c|}
\hline & & $1 L^{n}$ & $L^{n}$ \\
\hline Normal & . & 94 & 18 \\
\hline One L with SR . & . $\quad$. & I & I \\
\hline \multirow{2}{*}{ Two L's as dicentric } & . $\quad$. & I & $\ldots$ \\
\hline & & 83.5 per cent. & 16.5 per cent. \\
\hline
\end{tabular}

incapable of further mitosis. All of the anthers examined were at an early phase, less than 25 per cent. of the normal-looking pollen grains were binucleate. Later phases may show a higher frequency of pollen grains with the extra $\mathrm{L}^{n}$ chromosome but Darlington and Mather (1944) found that in a triploid hyacinth extra chromosomes had no effect on the rate of entry into pollen grain mitosis.

TABLE 9

Effect of extra $L^{n}$ chromosome from Rosalie on endosperm ${ }_{12-16}$ days after pollination

\begin{tabular}{|c|c|c|c|c|c|}
\hline $\begin{array}{c}\text { Endosperm } \\
\text { complement }\end{array}$ & $\begin{array}{c}\text { Total } \\
\text { endosperms }\end{array}$ & $\begin{array}{c}\text { Endosperms } \\
\text { with breakage }\end{array}$ & $\begin{array}{c}\text { Total } \\
\text { anaphases }\end{array}$ & $\begin{array}{c}\text { Anaphases } \\
\text { with breakage }\end{array}$ & $\begin{array}{c}\text { Per } \\
\text { cent. }\end{array}$ \\
\hline $3^{n}$ & 20 & 8 & 791 & 44 & 5.56 \\
$3^{n+L^{n}}$ & 1 & 1 & 33 & 15 & 45.45 \\
$3^{n+2 L^{n}}$ & 5 & 4 & 334 & 20 & 5.99 \\
\hline
\end{tabular}

There is no evidence relating the structural hybridity in the $\mathrm{L}$ chromosome with the apparent loss of extra $\mathrm{L}^{n}$ chromosomes in the pollen grains. This loss could account for all, or part of, the shortage of $\mathrm{L}^{n}$ chromosomes in the developing endosperms and embryos in Rosalie crosses (table 4). Some of this shortage may, however, result from early degeneration of the ovule.

There is evidence that additional $\mathrm{L}$ and $\mathrm{L}^{n}$ chromosomes, when accompanied by additional $\mathrm{M}$ and $\mathrm{S}$ chromosomes, benefit the 
developing seeds (fig. 2). But the endosperms where the extra chromosomes are all of the one type nearly always have chromosome breakage (figs. 3 and 4). Thus it appears that the addition of only one type of chromosome upsets the balance and results in chromosome breakage and early degeneration.

There is some evidence of this in the endosperms resulting from $2 x$ by Rosalie crosses (table 9). This may appear contrary to the fact that the extra $\mathrm{L}^{n}$ chromosome in Rosalie protects against observed X-ray breakage (La Cour, I952). These data are not necessarily contradictory, for the protection against observed X-ray breakage is associated with a changed physiological condition and acts presumably by favouring restitution. This altered physiology may, when acting in the special endosperm tissue, favour greater spontaneous chromosome breakage.

\section{THE MECHANISM OF ENDOSPERM FAILURE}

\section{(i) Sub-chromatid errors}

The first cytological abnormalities are errors in anaphase separation (plate I, fig. I). La Cour and Rutishauser (1953a) describe similar errors in Scilla endosperms after X-raying and consider that they result from sub-chromatid breakage and reunion. Earlier accounts have termed these errors point stickiness or "pseudo-chiasmata". Similar errors have arisen at meiosis after genotypic changes : mutations in maize (Beadle, 1932), segregation by inbreeding in rye (Lamm, I936; Müntzing and Akdik, I946) and hybridity in a species cross in Chorthippus (Klingstedt, I939). They are induced by environmental changes and are characteristic of the "primary" effects of X-rays (Darlington and La Cour, 1945). They also occur at mitosis and meiosis after chemical treatment with mustard gas (Darlington and Koller, I947), phenols (Levan and Tjio, 1948) and coumarin (Östergren, I 948).

In these hyacinth endosperms the errors were either intercalary or terminal and in one case involved non-homologous chromatids $\left(\mathrm{L}\right.$ and $\left.\mathrm{L}^{n}\right)$. There were more terminal than intercalary associations and, as has been suggested by Darlington and Upcott (I94I), some of these could result from failure of reproduction of the end genes.

Anaphase separation after sub-chromatid breakage and reunion results in either breakage of the chromatids or breakage of the association. When the association breaks it results in anaphase chromatids which are much attenuated between the centromere and the point of attachment and probably also accounts for the non-nucleolar constrictions or half-breaks occasionally observed at metaphase. In these endosperms the chromatids pulled apart more frequently than they broke. However, sub-chromatid associations formed after $\mathrm{X}$-raying more frequently resulted in chromatid breakage (La Cour, by personal communication). 


\section{(ii) Chromosome breakage}

Where anaphase separation results in mechanical breakage of the chromatids the broken ends are successively available for chromosome

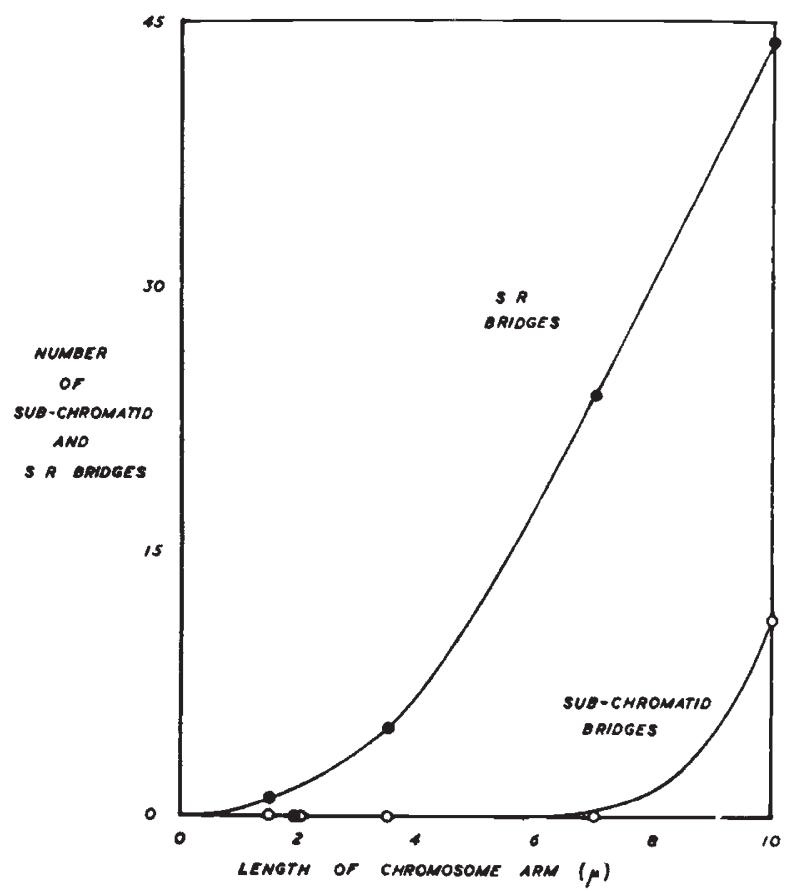

Fig. 6.-Relation of the length of chromosome arm with the number of sub-chromatid and SR bridges occurring in endosperm, various crosses (see table 2), 12 to 16 days after pollination.

TABLE 10

Comparison of sub-chromatid association and $S R$ bridges in $L, M$ and $S$ chromosomes in endosperms, 12 to 16 days after pollination. Correction for length and frequency will give $I: I: I$ ratio if distribution random. Chromosome lengths $L=19 \mu . \quad M=9 \mu$. $S=5 \mu . \quad\left(L=L+L^{n}\right)$

Ratio of $L: M: S$

\begin{tabular}{|c|c|c|c|c|}
\hline & $(2 x) \times(3 x)$ & $(2 x+6) \times(2 x)$ & $(2 x+6) \times(3 x)$ & $(3 x) \times(2 x+6)$ \\
\hline $\begin{array}{l}\text { Chromosome no. } \\
\text { Sub-chromatid B }+\dot{R} \\
\text { SR bridges }\end{array}$ & $\begin{aligned} 2 & : 1: 1 \\
33: 0 & : 0 \\
152: & 23: 5\end{aligned}$ & $\begin{aligned} 16: 6: 8 \\
\ldots: \\
7: 1: 0\end{aligned}$ & $\begin{array}{r}18: 7: 9 \\
3: 0: 0 \\
11: 0: 0\end{array}$ & $\begin{array}{r}18: 8: 9 \\
9: 0: 0 \\
6: 0: 1\end{array}$ \\
\hline \multicolumn{5}{|c|}{ Corrected for length and frequency } \\
\hline $\begin{array}{l}\text { Sub-chromatid } B+R \\
\text { SR bridges }\end{array}$ & $\begin{array}{c}4 \cdot 3: 0: 0 \\
20 \cdot 0: 12 \cdot 8: 5\end{array}$ & $0.9: 0.7: 0$ & $\begin{array}{l}0 \cdot 4: 0: 0 \\
1 \cdot 5: 0: 0\end{array}$ & $\begin{array}{l}1 \cdot 2: 0: 0 \\
0 \cdot 8: 0: 1\end{array}$ \\
\hline
\end{tabular}

reunion $\left(\mathbf{R}^{\prime \prime}\right)$, sister reunion $(\mathrm{SR})$ or chromatid reunion $\left(\mathbf{R}^{\prime}\right)(\mathrm{La}$ Cour, 1952). As breakage of a single anaphase bridge is the most frequent occurrence, $\mathrm{SR}$ is the most frequent consequence. This 
initiates the bridge-breakage-fusion cycle in the endosperm inferred by McClintock in maize (1941) and recently demonstrated in Lilium. The number of SR bridges was related to the length of the chromosomes (the longer the chromosome the more frequent the SR bridges) and sub-chromatid breakage only occurred in $\mathrm{L}$ and $\mathrm{L}^{n}$ chromosomes (table 10, fig. 6). This is in agreement with the results of Rees (1952), who showed centromere influence on the formation of subchromatid associations. It also suggests that the SR bridges are largely initiated by breakage of previous anaphase associations.

In the $\mathrm{L}$ and $\mathrm{L}^{n}$ chromosomes both the $\mathrm{SR}$ and sub-chromatid bridges occurred more frequently in nucleolar arms than in nonnucleolar arms (table II and fig. 7).

\section{TABLE II}

Comparison of sub-chromatid and $S R$ bridges in arms of $L$ and $L^{n}$ chromosomes in endosperms, 12-16 days after pollination

\begin{tabular}{|c|c|c|c|c|c|c|}
\hline & \multirow{2}{*}{$\begin{array}{l}\text { Endo- } \\
\text { sperms }\end{array}$} & \multirow{2}{*}{ Anaphases } & \multicolumn{2}{|c|}{$\begin{array}{l}\text { Ratio of chrs. arms } \\
\text { in endosperm }\end{array}$} & \multicolumn{2}{|c|}{$\begin{array}{l}\text { Number of anaphase } \\
\text { bridges }\end{array}$} \\
\hline & & & $\begin{array}{l}\text { Nucleolar } \\
\mathbf{L}^{n}\end{array}$ & $\frac{\text { Non-nucleolar }}{\mathbf{L}^{n} \quad \mathrm{~L}}$ & $\begin{array}{l}\text { Nucleolar } \\
\mathbf{L}^{n}\end{array}$ & $\frac{\text { Non-nucleolar }}{L^{n}}$ \\
\hline $\begin{array}{l}\text { Sub-chrd. associa- } \\
\text { tions }\end{array}$ & 6 & 29 & $\mathbf{I}$ & $\underbrace{1 \quad 7 \cdot 3}_{8 \cdot 3}$ & 8 & $\underbrace{3}_{21} 18$ \\
\hline \multicolumn{7}{|c|}{ Nucleolar : Non-nucleolar $\chi^{2}=8 \cdot 67$} \\
\hline SR bridges & 27 & 106 & $\mathbf{I}$ & $\underbrace{1-5 \cdot 7}_{6 \cdot 7}$ & I 7 & $\underbrace{3 \quad 26}_{29}$ \\
\hline \multicolumn{7}{|c|}{ Nucleolar : Non-nucleolar $\chi^{2}=23.66$} \\
\hline
\end{tabular}

Note.-2, 4, 8, etc., nuclei occurring together each with a bridge in the same chromosome arm were scored as one bridge.

McLeish (1952) has demonstrated a similar preference for SR in the nucleolar arm of Vicia faba after chromosome breakage induced by maleic hydrazide. It is interesting that chemically induced chromosome breakage and spontaneous sub-chromatid breakage both follow the same pattern in this respect and suggests that both may be due to an indirect effect on chromosome reproduction with which the nucleolus is intimately concerned. The prevalence of abnormalities in the nucleolar arm is further confirmed by the high proportion of rings and dicentrics which involve this chromosome (table I2). Rings and dicentrics, once formed, persist either by parallel separation or through the bridge-breakage-fusion cycle. It is notable here as in the Lilium endosperm that rings, in addition to persisting, tend to 
accumulate. As many as 7 rings were observed in the one anaphase, suggesting that special conditions of breakage or reunion were necessary for ring formation.

TABLE 12

Proportion of $L, M$ and $S$ chromosomes in endosperms 12-16 days after pollination, involved in cytological abnormalities other than sub-chromatid or SR bridges. All crosses from table 2. (Ratio $L: L^{n}: M: S$ approximately $3: 1: 2: 2$ )

\begin{tabular}{|c|c|c|c|c|c|}
\hline & Total & L & $L^{n}$ & $\mathbf{M}$ & $\mathbf{S}$ \\
\hline \multirow[t]{2}{*}{$\begin{array}{l}\text { centrics } \\
\text { ngs } \\
\text { lophase laggards } \\
\text { saks at centromere }\end{array}$} & $\begin{array}{r}38 \\
6 \\
7 \\
4\end{array}$ & $\begin{array}{r}23 \\
2 \\
1 \\
2\end{array}$ & $\begin{array}{l}6 \\
4 \\
6 \\
2\end{array}$ & $\begin{array}{l}5 \\
\cdots \\
\cdots \\
\cdots\end{array}$ & $\begin{array}{l}4 \\
\cdots \\
\cdots \\
\cdots\end{array}$ \\
\hline & 55 & 28 & 18 & 5 & 4 \\
\hline
\end{tabular}

* 19 dicentrics, $3^{8}$ centromeres from $3^{8}$ chromosomes. All $\mathrm{M}$ and $\mathrm{S}$ are coupled with $\mathrm{L}$ or $\mathrm{L}^{n}$

Lagging telophase chromatids ( $f$. Dowrick, 1953; Haque, 1952 ; Kihlman, 1952 ; Mota, 1952) and breakage at the centromere disproportionately often, involved the $\mathrm{L}^{n}$ chromosome.

Although breakage did accumulate, the "snowballing" effect of breakage inducing more breakage, which culminates in degeneration, was less apparent in the hyacinth endosperm than in the lily.

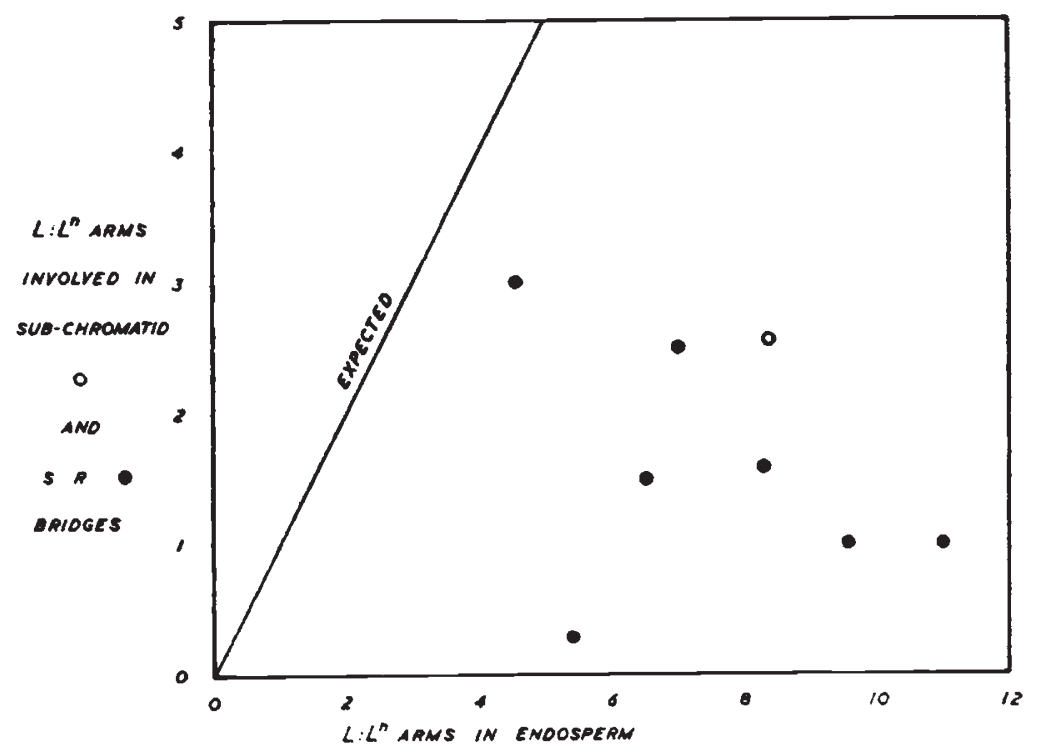

Fic. 7.- Ratio of non-nucleolar to nucleolar arms involved in sub-chromatid and SR bridges in endosperms. Various crosses (see table 2), 12 to 16 days after pollination.

Although breakage is the result of unbalance (chromosomal, genic or cytoplasmic) the chromosome complement of the hyacinth is no doubt buffered against the effects of this breakage and further abnormalities accumulate only slowly. This suggests that the balance 
of the hyacinth chromosomes may extend, beyond individual chromosomes, to internal balance of broken or deficient chromosomes. Two observations support this suggestion. First, healing against reunion occurs. Although the bridge-breakage-fusion cycle operates in these endosperms, healing against reunion occasionally results in failure of bridge formation and conversion of rings and dicentrics into ordinary chromosomes. It was not possible to estimate the frequency of this
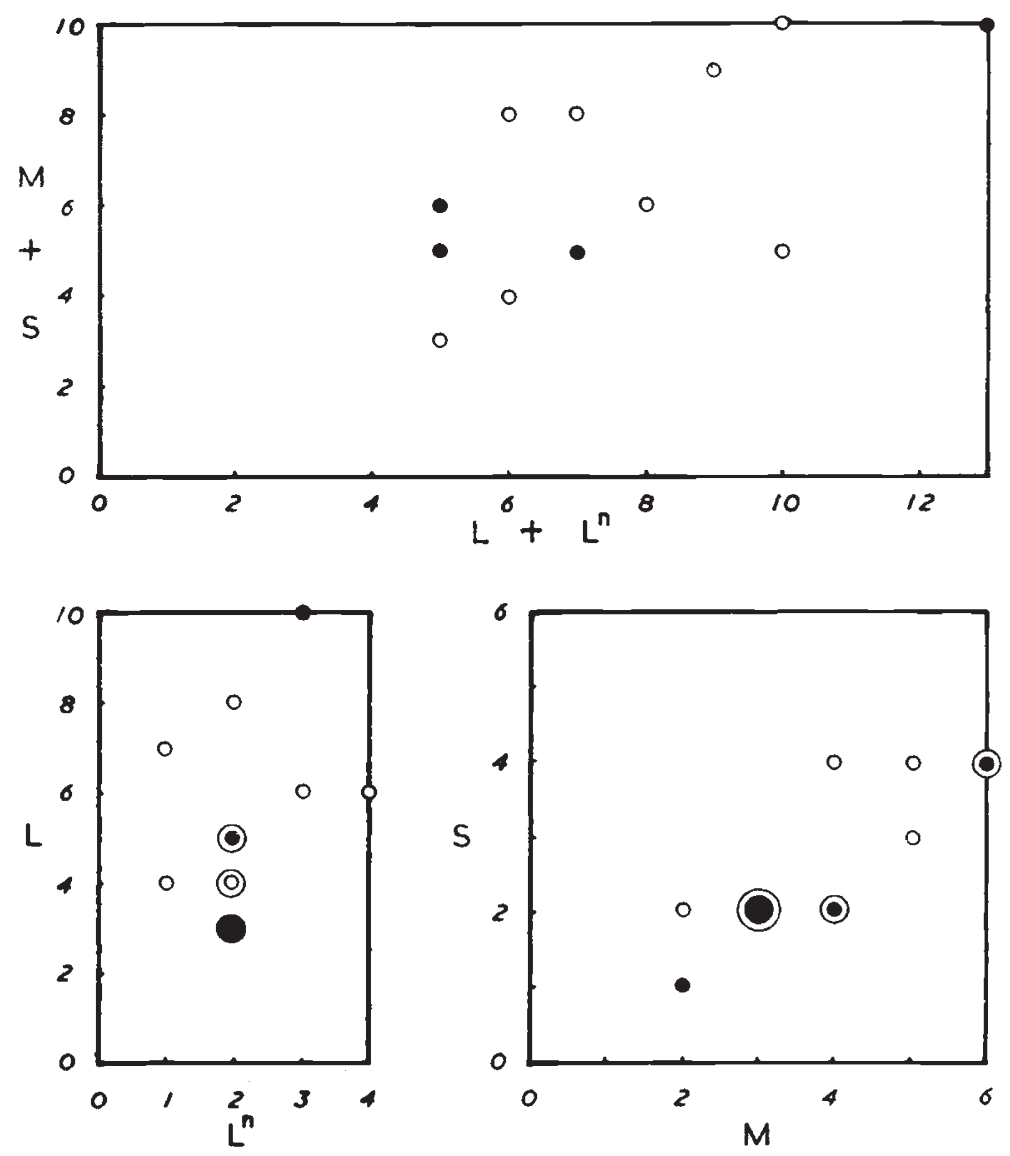

Fig. 8.--Relation between $L, M$ and $S$ chromosomes in aneuploid nuclei resulting from split spindles, occurring in endosperms 12 to 16 days after pollination. Each group of aneuploid nuclei represented by circle. Solid circles indicate chromosome breakage.

healing against reunion. Secondly, a deficient chromosome was transmitted through the pollen. Where the diploid $H$. orientalis with a telocentric and deficient $\mathrm{S}_{2}$ chromosome was used as a pollen parent the deficient chromosome was transmitted by the pollen to the embryo and endosperm in four of the eight crosses examined.

(iii) Spindle abnormalities

A general spindle abnormality is indicated by the lack of wall formation during the free-nucleate stage of endosperm development, 
but in addition fusion (plate II, fig. I) and splitting (plate II, fig. 2) of spindles occurred. Fusion of adjacent spindles is one of the mechanisms for the formation of the highly polyploid nuclei commonly observed in endosperm. Evidence that this occurs is given by such nuclei occurring in the absence of chromosome breakage and by the presence of composite endosperms : e.g. hexaploid nuclei with a single dicentric resulting from the fusion of a normal triploid nucleus and one containing a dicentric. The three types all occurring in the one endosperm (plate II, fig. 5).

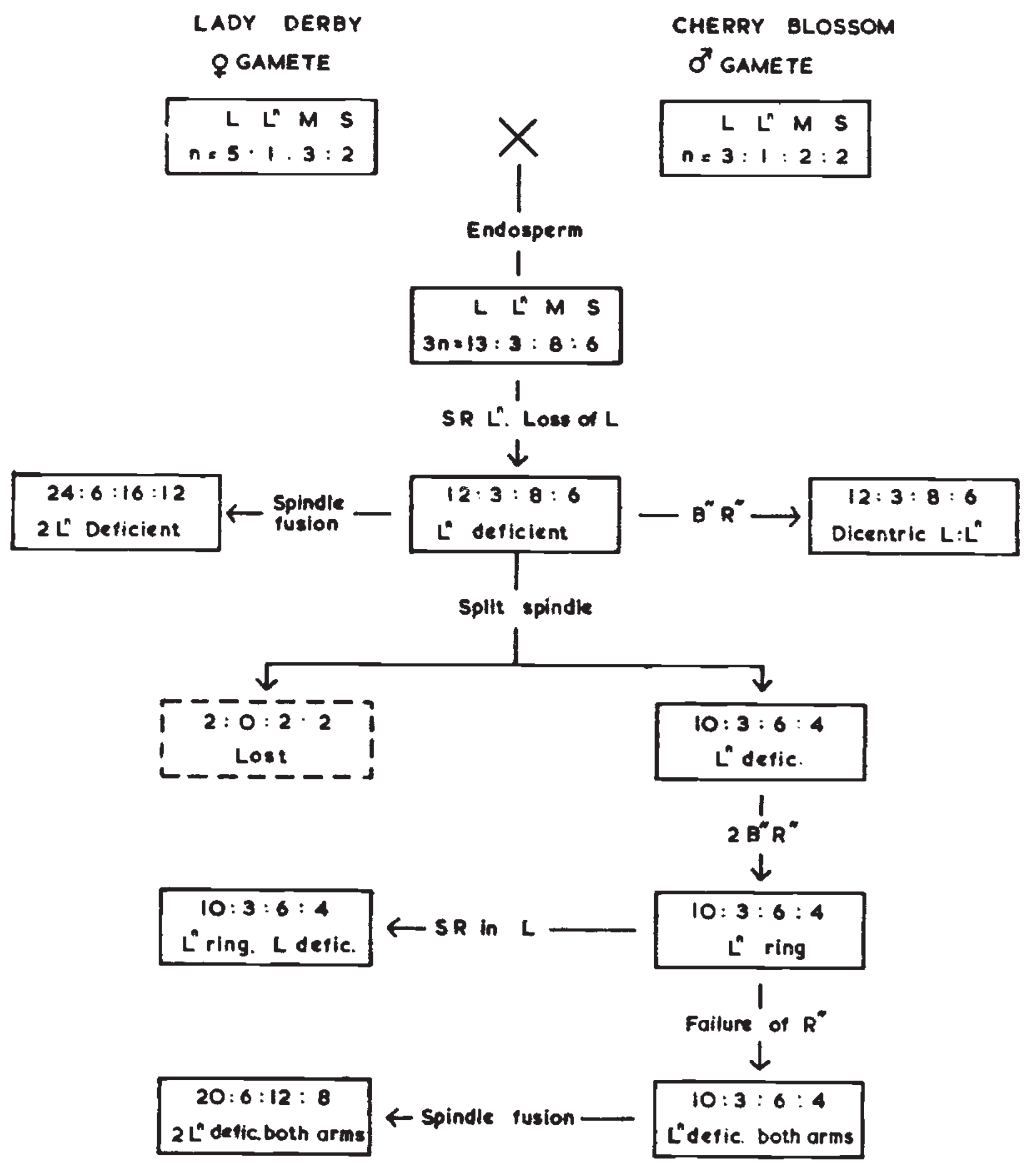

FIG. 9.-Diagram representing changes which occurred in one endosperm. Fixation I5 days after pollination. Changes inferred from complements represented in endosperm. Note $\mathrm{L}^{n}$ deficient means $\mathrm{L}^{n}$ chromosome which has lost a portion of one arm. It does not mean that the complement is deficient in one $\mathrm{L}^{n}$ chromosome.

Highly polyploid nuclei can also be formed by anaphase bridges failing to break. The interphase nuclei remain connected and at the subsequent metaphase, if mitoses are synchronised, restitution occurs (plate II, fig. 3).

In the aneuploid nuclei resulting from split spindles the number relationships between the $\mathrm{L}, \mathrm{L}^{n}, \mathrm{M}$ and $\mathrm{S}$ chromosomes previously demonstrated were also apparent (fig. 8). Even though these nuclei 
were side by side with the normal nuclei and in a common cytoplasm the highly unbalanced types failed to persist. No aneuploid nucleus was completely deficient in any one type of chromosome and the lowest total number was equivalent to the haploid number.

The frequency of spindle abnormalities increased with increasing chromosome number of the endosperm but, as with sub-chromatid and chromosome breakage, the endosperms resulting from diploid by diploid crosses were not free from irregularities (fig. 5).

The development of combined abnormalities in an endosperm from a triploid by diploid cross is illustrated in fig. 9 .

\section{AGED POLLEN}

All the crosses so far discussed were made with freshly dehisced pollen. Some crosses were attempted with pollen which had been

TABLE 13

Random distribution of $X$-ray breakage in an endosperm with chromosome complement $L$ 12,

$L^{n} 4, M 6, S 6$ (Rosalie $\times$ King of the Blues). Dose $100 \mathrm{r}, \mathrm{r}_{3}$ days after pollination Fixation 24 hours after irradiation

\begin{tabular}{|l|c|c|c|c|c|c|c|}
\hline & L & & \multicolumn{2}{|c|}{$\mathrm{L}^{n}$} & & & \\
& & Non-nuc. & Nuc. & & S & $\begin{array}{c}\text { Total } \\
\text { nuclei }\end{array}$ \\
\hline SR bridges with fragments & 30 & 5 & 9 & 5 & I & 44 \\
\hline
\end{tabular}

Nucleolar : Non-nucleolar arms of $\mathrm{L}$ chromosomes

$$
x^{2}=2.55 \quad \mathrm{P}=0.1 \quad \mathrm{~N}-\mathrm{S}
$$

$\mathrm{L}: \mathrm{M}: \mathrm{S}$ using length (19:9:5)/frequency $(32: 12: 12)$ ratio

$$
x^{2}=3.28 \quad \mathrm{P}=0.2 \mathrm{~N}-\mathrm{S}
$$

stored at $6^{\circ} \mathrm{C}$. over $\mathrm{CaCl}_{2}$ for periods varying from 16 to 34 days. The seed set following such pollinations was greatly reduced. Some developing ovules were, however, obtained.

The endosperms from pollen stored for 16 to i 8 days had no more abnormalities than the controls. But from pollen stored for 34 days two endosperms showed abnormalities of kinds not observed in the control. One had chromosome and spindle abnormalities, and also single lagging $\mathrm{L}^{n}$ anaphase chromatids, in adjacent nuclei. The other, examined 16 days after pollination, still had an unfertilised egg cell. What appeared to be a sperm nucleus was lying beside the haploid egg nucleus. The endosperm consisted of one highly polyploid nucleus which was showing mass chromosome breakage (plate II, fig. 6).

\section{X-RAY EXPERIMENTS}

$\mathrm{X}$-ray-induced chromosome breakage in hyacinth endosperms was examined to see whether its distribution was random or concentrated in particular chromosomes and arms like the spontaneous breakage. 
An endosperm fixed 24 hours after irradiation was scored for anaphase bridges with accompanying fragments (table I3). There was no significant concentration of breakage in either the long chromosomes or the nucleolar arms. The method of scoring seems to be valid but it is open to criticism on the grounds that no suitable controls were available because of the high level of spontaneous breakage in these hyacinth endosperm (fig. 5). Restricting the analysis to cells which showed bridges and fragments at the first division after treatment excludes most of the persisting bridges, which result from earlier spontaneous breakage, but it includes those which still have fragments. This would account for the slight but not significant concentration of bridges involving long chromosomes and nucleolar arms (table i 3 ).

Other endosperms fixed 48 and I 20 hours after irradiation showed all the mitotic and spindle abnormalities observed after spontaneous chromosome breakage; sub-chromatid breakage, SR bridges, dicentrics, rings, reproduced fragments, micronuclei, highly polyploid and aneuploid nuclei. The effect after I 20 hours was like the mass breakage which occurred spontaneously in Lilium endosperms.

In root tips the "primary effects" of X-rays which induce subchromatid breakage last only a few hours (La Cour and Rutishauser, 1953a). However, in these endosperms, sub-chromatid breakage occurred up to I 20 hours after X-ray treatment. This indicates that the gross physiological disturbances produced by irradiations have a more lasting effect in this special and hybrid tissue.

\section{DISCUSSION}

\section{(i) Spontaneous chromosome breakage}

In these hyacinths the abnormalities in the endosperm begin with sticking of the anaphase chromatids. Anaphase movement results in mechanical breakage of the sticking chromatids. The breakage is recurrent owing to the bridge-breakage-fusion cycle. I consider that these primary bridges largely, if not wholly, result from sub-chromatid breakage and reunion.

Prolonged cold treatment induces similar errors in anaphase separation of the heterochromatic segments in Trillium (Darlington and La Cour, 1940; Kurabayashi, 1952). No heterochromatic segments were visible in these hyacinth endosperms, even after cold treatment, but if heterochromatin is associated with nucleic acid starvation the rapid mitotic rate of the endosperm may induce a condition approaching nucleic acid starvation and make the chromosomes liable to errors during reproduction.

The predominance of sub-chromatid breakage in the nucleolar arms and the centromere control of these effects further indicates a relationship between them and chromosome reproduction. La Cour and Rutishauser (1953a) have shown that X-ray-induced sub-chromatid 
breakage is confined to prophase and they suggest that these errors occur during reproduction (I953b). If these errors are reproductive errors then chromosome reproduction must occur during prophase for the subsequent mitosis.

The frequency of sub-chromatid bridges is correlated with the number of secondary SR bridges. Both increase with chromosome number of the particular endosperm in the same way as do spindle abnormalities (fig. 5). The similar behaviour of the chromosome and the spindle abnormalities suggests that the control of sub-chromatid breakage and reunion is exercised through the cytoplasm and is determined by nuclear-cytoplasmic relationships ( $c f$. Mather, I948).

\section{(ii) Endosperm failure}

We have seen that in hyacinths the cycle of chromosome breakage begins with spontaneous sub-chromatid breakage and persists as chromosome breakage through the bridge-breaking-fusion cycle.

Unless the system is buffered against the effects of loss, by balance between and within chromosomes, the abnormalities will induce more abnormalities and the endosperm will degenerate. In the more balanced complements the abnormalities increase only slowly and the young seeds survive. It seems that the most unbalanced endosperms are those where the extra chromosomes are all, or predominantly of the one type. I suggest that because of the lack of a buffering system the grossly unbalanced endosperms degenerate soon after fertilisation. Endosperm failure can thus be a selection mechanism eliminating unbalanced plants.

The effect of this spontaneous chromosome breakage on hyacinth endosperms thus seems to depend on three factors :-

(i) The number of normal nuclei present when breakage begins.

(ii) The chromosome balance in these nuclei.

(iii) The number of chromosomes in the nuclei.

Is the sequence of events, commencing with mitotic abnormalities and leading to endosperm failure and embryo abortion peculiar to hyacinths or can it be more generally applied?

Many reports of endosperm failure include accounts of chromosome breakage and mitotic abnormalities (Beaudry, I95I ; Boyes and Thompson, I937; Brock, I954; Cooper and Brink, I944; Kihara and Nishiyama, I932 ; Landes, I939; Thompson and Johnson, 1945). These abnormalities frequently occur after crossing plants of different chromosome number. Abnormal endosperms occur in crosses where there are wide genetic differences (e.g. hybrids between species) and in crosses where there is little genetic difference between the parents (e.g. diploid $\times$ autotetraploid).

Even in the diploid-diploid crosses of the hyacinth there is considerable endosperm failure. Genetic character therefore influences the breakdown. But the failure increases where the chromosome 
number of the endosperm is higher. The abnormalities must therefore be controlled at the chromosomal level as well as at the genic level.

Endosperm failure sometimes results from selfing plants which are normally outbreeders. This is essentially an incompatibility mechanism, but it has the important difference that it entails wastage of reproductive materials, and as such is inefficient. In Medicago sativa (Cooper and Brink, I940) and Secale cereale (Landes, I939) endosperm failure is combined with a slower pollen tube growth so that relatively few ovules are fertilised. However, in Gasteria verrucosa (Sears, I937) and in Theobroma cacao (Knight and Rogers, I953) there is no difference in the rate of pollen tube growth between compatible and incompatible pollinations. These are examples of sporaphytic control of incompatibility with the site of action in the fertilised ovule rather than in the style. They indicate also that the medium carrying the immediately determining factor is not the nucleus but the cytoplasm.

Brink and Cooper (I 944) and Beaudry (I95I) after crossing Hordeum jubatum by Secale cereale and Elymus virginicus by Agropyron repens found abnormalities in both endosperm and antipodals. They postulate a mechanism of endosperm failure involving the antipodals as intermediaries. No detailed studies have been made of the behaviour of the antipodal nuclei in the hyacinth crosses, but occasionally enlarged antipodal nuclei were observed. Thompson and Johnston (I945) failed to find any antipodal abnormalities associated with endosperm failure after crossing Hordeum vulgare by Secale cereale. In all the reported cases where abnormalities occurred in the antipodals some prior endosperm development had occurred so it seems likely that these abnormalities were a secondary rather than a primary effect.

Rappaport et al. (1950a,b) report seed failure in interspecific and diploid by autotetraploid Datura crosses. These seed failures are characterised by failure of the endosperm and embryo and proliferation of the endothelium, but the first abnormalities occur in the endosperm (Blakeslee et al., I953).

Thus we can conclude that the sequence of events, beginning with spontaneous chromosome breakage in the endosperm and culminating in endosperm failure and embryo abortion, occurs far more widely than in these hyacinths and is a common cause of seed failure after crossing.

\section{SUMMARY}

I. Diploid, hypo-triploid and triploid varieties of Hyacinthus orientalis with different numbers of $\mathrm{L}, \mathrm{L}^{n}, \mathrm{M}$ and $\mathrm{S}$ chromosomes, were used in crossing.

2. Rosalie, a trisomic for $\mathrm{L}^{n}$, is a structural hybrid with inversions in two $\mathrm{L}$ chromosomes. The extra $\mathrm{L}^{n}$ chromosome appeared in only I6. 5 per cent. of the cells at pollen grain mitosis.

3. Endosperm failure and subsequent embryo abortion occur after crossing. Spontaneous chromosome breakage and spindle abnormalities (resulting in polyploidy and aneuploidy) occur in these endosperms. 
4. (i) The primary errors are breakage and reunion of subchromatids and possibly failure of the end gene to reproduce. These result in chromosome breakage; they lead to secondary errors in subsequent mitoses.

(ii) The centromere and the nucleolar organiser influence these sub-chromatid errors, which can therefore be related with chromosome reproduction. This influence is not found after X-raying.

5. (i) The range of chromosome balance in the developing embryos and endosperms agrees with that in the commercial hyacinth varieties.

(ii) In balanced forms some abnormalities occur but in unbalanced forms abnormalities accumulate and culminate in degeneration of the endosperm. They become more frequent as the chromosome number of the endosperm is increased.

(iii) An unusual internal balance in the hyacinth chromosomes is indicated by the unique transmission of a deficient chromosome by the haploid pollen; and by the healing against reunion after chromosome breakage, which occurs in these hyacinths but not in maize.

6. X-rayed and aged pollen induce abnormalities of mitosis in the endosperm.

7. The reduced spiralisation of the endosperm chromosomes reveals staining bodies in some of the nucleolar constrictions. Different varieties are homozygous or heterozygous for this condition.

Acknowledgments.-This work was done while at the John Innes Horticultural Institution, Hertford, England, on a Studentship from the Commonwealth Scientific and Industrial Research Organization, Australia. I wish to express my thanks to Professor G. D. Darlington for facilities and helpful advice.

\section{REFERENCES}

ANDERson, L. E. 1936. Mitochondria in the life cycle of certain higher plants. Amer. F. Bot., 23, 490-500.

BEADLE, G. W. 1932. A gene for sticky chromosomes in Zea mays. Z.I.A.V., 63, 195-217.

BEAUDRY, J. R. 1951. Seed development following the mating Elymus virginicus L. $\times$ Agropyron repens (L) Beauv. Genetics, 36, 109-133.

BELling, J. 1924. Distribution of pollen grains of the triploid hyacinth. Amer. Nat., $5^{8}, 44^{0}-44^{6}$.

Boyes, J. W., AND THompson, w. P. 1937. The development of the endosperm and embryo in reciprocal interspecific crosses in cereals. 7. Genet., 34, 203-227.

blakeslee, A. F., SAtina, s., AND RIETSEma, J. 1953. Further studies on incompatibility crosses in Datura. Proc. 9 Int. Congr. Genet. (in press).

BRINK, R. A., AND COOPER, D. c. 1944. The antipodals in relation to abnormal endosperm behaviour in Hordeum jubatum $\times$ Secale cereale hybrid seeds. Genetics, 29, $391-406$.

BRINK, R. A., AND COOPER, D. C. 1947. The endosperm in seed development. Bot. Rev., 13, 423-54I.

BROCK, R. D. 1954. Spontaneous chromosome breakage in Lilium endosperm. Ann. Bot., N.S., 18, 7-14.

COOPER, D. C., AND BRINK, R. A. 1940. Partial and self-incompatibility and the collapse of fertile ovules as factors affecting seed formation in alfalfa. $\mathcal{J}$. agric. Res., 6o, 453-472. 


\section{Plate I}

Endosperns of hyacinth, various variety crosses. Fixation 12 to 16 days after pollination, in Carnoy fluid $(6: 3: 1)$, stained with Feulgen reagent. Dissected and squashed in 45 per cent. acetic acid.

FIG. I.-Sub-chromatid bridge at anaphase. $\times 900$.

Fig. 2.-SR bridge in $\mathrm{L}^{n}$. Note normal length of trabant top left. Short trabants in centre and long trabants on right demonstrate the effects of unequal breaking in bridgebreakage-fusion cycle. Note staining areas in nucleolar constriction, centre and right ; long non-staining constriction, top left. $\times 900$.

Fig. 3.-Interlocked dicentric involving $\mathrm{L}$ and $\mathrm{L}$ at anaphase. $\times 900$.

Fig. 4.- Ring chromosome involving $\mathrm{L}^{n}$ at anaphase. $\times 900$.

Fig. 5.-Pollen grain mitosis in Rosalie showing bridge in $\mathrm{L}$ chromosome. Complement $\mathrm{L}_{3}, \mathrm{~L}^{n_{2}}, \mathrm{M}_{2}, \mathrm{~S}_{2} . \times 1350$.

Fig. 6.-First anaphase of meiosis in Rosalie showing inversion crossing-over bridge and fragment in $\mathrm{L}$ chromosome and univalent $\mathrm{L}^{n}$ chromosome. $\times 135^{\circ}$. 


\section{Plate II}

Endosperm of hyacinth, various variety crosses. Technique-as for plate I

Fig. I.-Fusion of adjacent spindles at anaphase to produce highly polyploid nuclei. $\times 900$.

FIG. 2.- Splitting of spindle at anaphase. This will result in aneuploid nuclei which if they are balanced will persist in endosperm (see fig. 4). $\quad \times 900$.

Fig. 3.-Two metaphases connected by unbroken bridge from previous division. This will probably result in restitution and high polyploidy. $\times 900$.

FIG. 4.--Aneuploid anaphase $\mathrm{L}_{3}, \mathrm{~L}_{2} \mathbf{n}_{2}, \mathbf{M}_{4}, \mathrm{~S}_{2}$. This is one of the products of a split spindle (fig. 2) persisting in endosperm. $\times 900$.

FIG. 5. - $3 x$ and $6 x$ nuclei persisting in endosperm. Each nucleus carries the same dicentric and the $6 x$ arose by fusion of spindles of adjacent nuclei ( $3^{x}$ normal plus $3^{x}$ including a dicentric). $\times 450$.

Fig. 6.-Ovule i 6 days after pollination with aged pollen (stored at $6^{\circ} \mathrm{C}$. for 34 days). Unfertilised egg cell in prophase with a sperm nucleus beside it. Lower is the endosperm : one polyploid nucleus showing mass breakage. Antipodals not shown. In centre are extraneous nucellar nuclei. $\times 200$.

FIG. 7.-Spontaneous chromosome breakage at the centromere (misdivision) of $\mathrm{L}^{n}$ chromosome. Nucleolar arms showing some centromere activity but delayed. Non-nucleolar arms acentric. $\times 900$. 


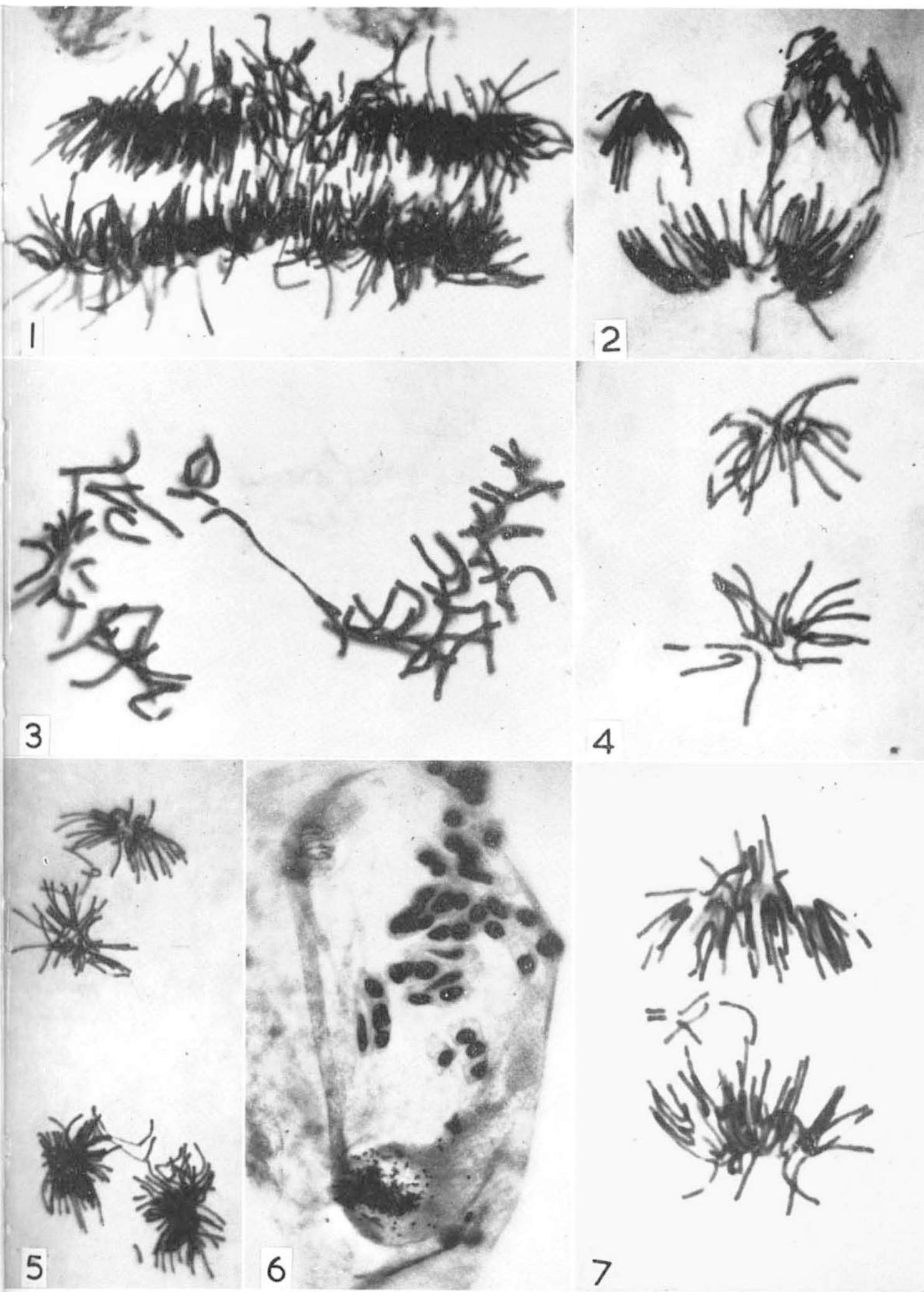


COOPER, D. C., AND BRINK, R. A. 1944. Collapse of the seed following the mating of Hordeum jubatum $\times$ Secale cereale. Genetics, 29, 370-390.

Darlington, C. D. 1926. Chromsome studies in the Scillex. 7. Genet., 16, 237-251. DARLINGton, C. D. 1929. Meiosis in polyploids. II. Aneuploid hyacinths. $\mathcal{J}$. Genet., 21, I 7-56.

DARLINGTON, C. D. 1937. Recent advances in Cytology. 2nd Ed. London : Ghurchill. DARLINGTON, C. D., HAIR, J. B., AND HURCOMBE, R. 195I. The history of the garden hyacinths. Heredity, 5, 233-252.

DARLINGTON, C. D., AND KOLLER, P. C. 1947. The chemical breakage of chromosomes. Heredity, 1, 187-221.

DARLINGTON, C. D., AND LA COUR, L. F. 1940. Nucleic acid starvation of chromosomes in Trillium. 3. Genet., 40, 185-213.

DARlington, C. D., AND LA Cour, L. F. 1945. Chromosome breakage and the nucleic acid cycle. 3. Genet., 46 , 180-267.

DARLINGTON, C. D., AND LA COUR, L. F. 1947. The handling of chromosomes. 2nd Ed. London : Allen and Unwin.

darlington, C. D., AND mather, K. 1944. Chromosome balance and interaction in Hyacinthus. 7. Genet., 46, 52-61.

DARLINGTON, C. D., AND UPCOTT, M. B. I94I. Spontaneous chromosome change. J. Genet., 4I, 297-338.

DowRICK, G. J. I 953 . The chromosomes of Chrysanthemum. II. Garden varieties. Heredity, 7, 59-72.

haque, A. 1952. The irradiation of meiosis in Tradescantia. Heredity, 6, sup., $57-75$.

KIHARA, N., AND NISHYAMA, I. I932. The genetics and cytology of certain cereals. III. Different compatibility in reciprocal crosses of Avena with special reference to tetraploid hybrids between hexaploid and diploid species. Fap. Four. Bot., $6,245-305$.

KIHLMAN, B. 1952. A survey of purine derivatives as inducers of chromosome changes. Hereditas, 38 , I $15-127$.

KLINGSTEDT, H. 1939. Taxonomic and cytological studies on grasshopper hybrids. 7. Genet., 37, 389-420.

KNIGHT, R., AND ROGERS, H. H. 1953. Sterility in Theobroma cacao. Nature, 172, I64. KURABayashi, M. 1952. Differential reactivity of chromosomes in Trillium. $\mathcal{J}$. Fac. Sci. Hokkaido Univ. Ser. V., 6, 233-248.

LA CouR, L. F. 1952. The physiology of chromosome breakage and reunion in Hyacinthus. Heredity, 6, sup., $163^{-1} 79$.

LA COUR, L. F., AND RUTishaUSer, A. 1953a. Chromosome breakage experiments with endosperm. Sub-chromatid breakage. Nature, 172, 501 .

LA COUR, L. F., AND RUTiShauser, A. I953 $b$. Chromosome breakage experiments with endosperm. Proc. 9 Int. Congr. Genet. (in press).

LAMM, R. 1936. Cytological studies on inbred rye. Hereditas, 22, 21 7-240.

LANDES, м. 1939. The causes of self-sterility in rye. Amer. F. Bot., 26, 567-57 I.

LEVAN, A., AND TJIO, J. H. 1948. Induction of chromosome fragmentation by phenols. Hereditas, 34, 453-484.

McClintock, B. I94I. The stability of broken ends of chromosomes in Zea mays. Genetics, 26, 234-282.

McLEISH, J. 1952. The action of maleic hydrazide in Vicia. Heredity, 6, sup., I 25-1 47.

MATHER, K. 1948. Significance of nuclear change in differentiation. Nature, 16I, $872-878$.

мота, м. 1952. The action of seed extracts on chromosomes. Arch. Pat. Lisboa, $24,336-357$.

MüntZING, A., AND AKDIK, s. I948. Cytological disturbances in the first inbred generation of rye. Hereditas, 34, 485-509. 
östergren, G. 1948. Chromosome bridges and breaks by coumarin. Bot. Notiser, No. $4,376-380$.

RAPPAPORT, J., SATINA, S., AND BlAKesleE, A. F. 1950 $a$. Ovular tumors and inhibition of embryo growth in incompatible crosses of Datura. Science, III, 276-277.

RAPPAPORT, J., SATINA, S., AND BLAKesLeE, A. F. 1950 $b$. Extracts of ovular tumors and their inhibition of embryo growth in Datura. Amer. F. Bot., 37, 586-595.

REES, H 1952. Centromere control of chromosome splitting and breakage. Heredity, 6, sup., 235-245.

SEARS, E. R. 1937. Cytological phenomena connected with self sterility in plants. Genetics, 22, I30-181.

THOMPSON, W. P., AND JOHNSTON, D. 1945. The cause of incompatibility between rye and barley. Canad. F. Res., C. 23, 1-15. 